\title{
Incompatible, not volatile: the behaviour of nitrogen in extrusive and plutonic igneous rocks and minerals
}

\author{
TOBY J. BOOCOCK ${ }^{1}$, GRANT M. BYBEE ${ }^{2}$, RAMONA \\ KOENIG $^{1}$, SAMI MIKHAIL ${ }^{1}$, JULIE PRYTULAK ${ }^{3}$, PAUL S. \\ SAVAGE $^{1}$, CHRISTIAN SCHRÖDER ${ }^{4}$ AND EVA E. \\ STÜEKEN $^{1}$ \\ ${ }^{1}$ University of St Andrews \\ ${ }^{2}$ University of the Witwatersrand \\ ${ }^{3}$ Durham University \\ ${ }^{4}$ University of Stirling \\ Presenting Author: tjb7@st-andrews.ac.uk
}

Disentangling the history of nitrogen $(\mathrm{N})$ in the continental crust is imperative for reconstructing the evolution of atmospheric pressure and planetary habitability over geologic timescales. Significant nitrogen can be stored in igneous materials, reflecting either a downwards conversion of atmospheric $\mathrm{N}_{2}$ into silicate-bound phases (e.g. as $\mathrm{N}^{3-}, \mathrm{NH}_{2}^{-}$, $\mathrm{NH}^{4+}$ ) or an upwards enrichment of nitrogen as an incompatible trace element (e.g. not $\mathrm{N}_{2}$ ) in mantle-derived differentiated melts. Here we present new data from two case studies to explore how nitrogen behaves during magmatic differentiation and within evolved plutonic rocks and minerals. First, we utilise a geologically young and well characterised differentiation suite from Hekla, Iceland, to show that nitrogen is behaving as an incompatible lithophile element during basalt-rhyolite differentiation at Hekla. These data show how nitrogen concentrations of $\sim 25 \mu \mathrm{g} / \mathrm{g}$ in evolved silicate materials can be generated by magmatic differentiation alone, with no need for the assimilation of crustal nitrogen. This enrichment can possibly explain ca. $45 \%$ of published nitrogen data from evolved plutonic rocks. Therefore, we find that magmatic differentiation is an underappreciated process for enriching nitrogen in the continental crust. We then take this one step further and present a detailed petrological and isotopic study of nitrogen geochemistry of minerals (biotite, orthoclase and plagioclase) and bulk rock in a zoned granitic pluton (Loch Doon, SW Scotland). Here our results reveal complex mineral-mineral partitioning and associated equilibrium stable isotopic fractionation, and we posit that the granitic nitrogen reservoir cannot be represented by a single mineral phase. All in all, the behaviour of nitrogen in igneous rocks is complex, and we will present evidence to suggest that the primary igneous portion of Earth's crust may store more nitrogen than current estimates propose. 